\title{
CORRECTION
}

\section{Correction to: Cardiovascular Risks, Bleeding Risks, and Clinical Events from 3 Phase III Trials of Pirfenidone in Patients with Idiopathic Pulmonary Fibrosis}

Marilyn K. Glassberg · Steven D. Nathan · Chin-Yu Lin •

Elizabeth A. Morgenthien · John L. Stauffer · Willis Chou •

Paul W. Noble

Published online: September 9, 2019

(c) The Author(s) 2019

Correction to: Adv Ther

https://doi.org/10.1007/s12325-019-01052-y

In the original publication the colors of Fig. 2 have been switched. The corrected Fig. 2 is given below

The original article can be found online at https://doi. org/10.1007/s12325-019-01052-y.

M. K. Glassberg ( $\bowtie)$

University of Miami Health System, Miami, FL, USA

e-mail: MGlassbe@med.miami.edu

S. D. Nathan

Inova Fairfax Hospital, Falls Church, VA, USA

C.-Y. Lin · E. A. Morgenthien · J. L. Stauffer

Genentech, Inc., South San Francisco, CA, USA

W. Chou

FibroGen, San Francisco, CA, USA

P. W. Noble

Cedars-Sinai Medical Center, Los Angeles, CA, USA 


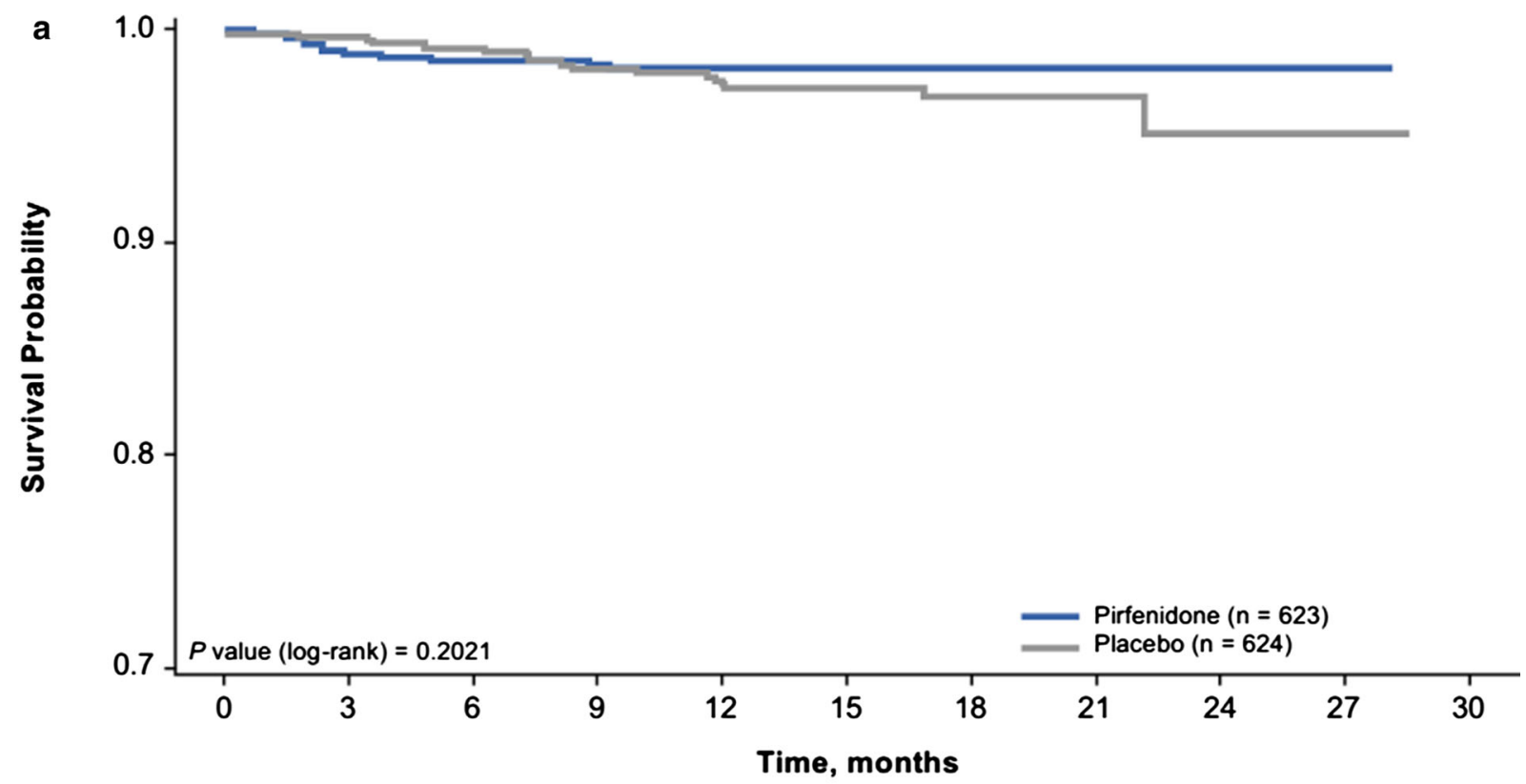

\section{No. at Risk}

$\begin{array}{rllllllllll}\text { Pirfenidone } & 623 & 607 & 579 & 546 & 532 & 293 & 162 & 87 & 20 & 2 \\ \text { Placebo } & 624 & 611 & 591 & 563 & 540 & 293 & 138 & 77 & 22 & 3\end{array}$

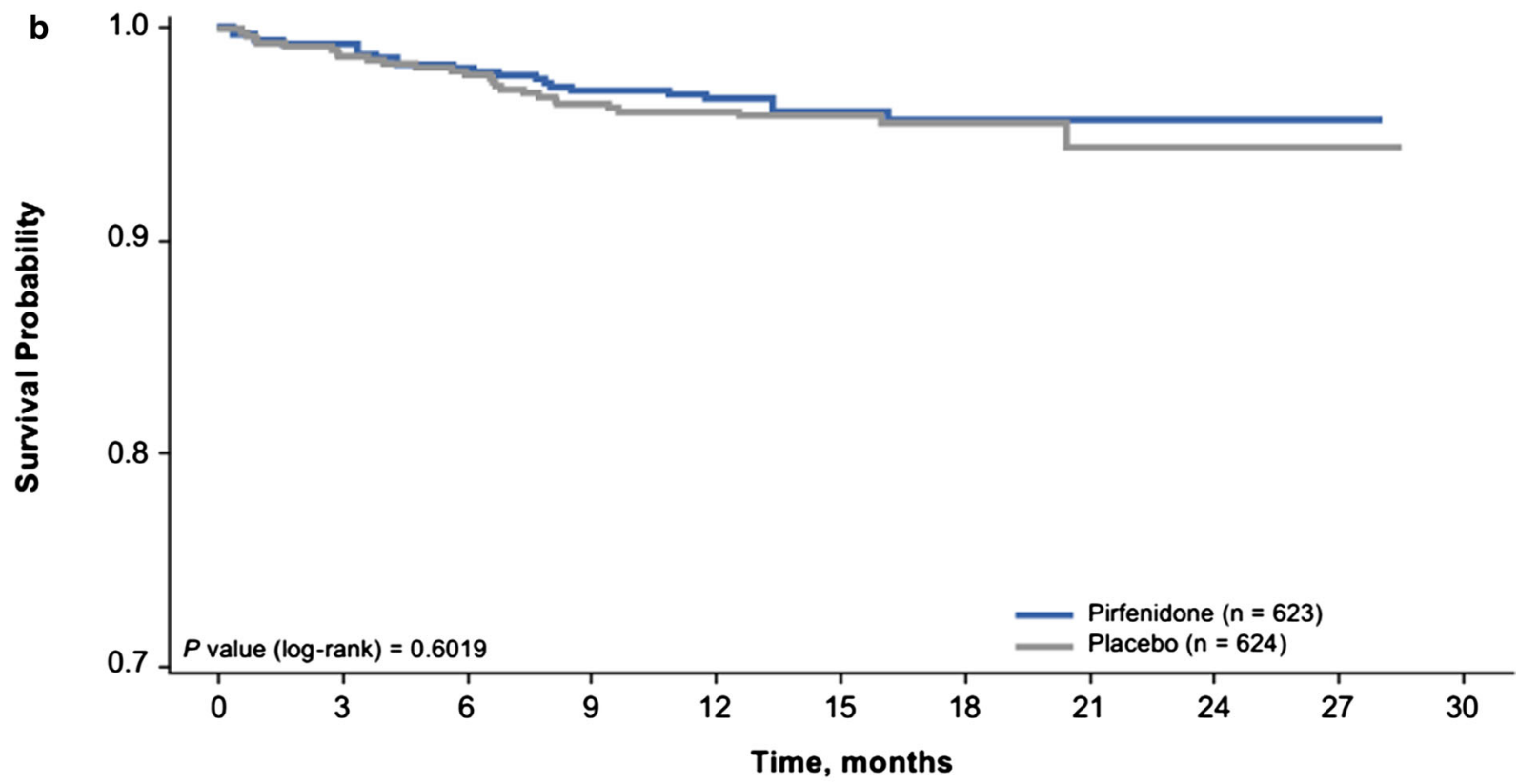

No. at Risk

$\begin{array}{rllllllllll}\text { Pirfenidone } & 623 & 607 & 572 & 536 & 520 & 283 & 157 & 84 & 20 & 2 \\ \text { Placebo } & 624 & 602 & 581 & 553 & 530 & 288 & 140 & 79 & 22 & 3\end{array}$

Fig. 2 Time to first major adverse cardiac event-plus (a) and time to first bleeding event (b) 
Open Access. This article is distributed under the terms of the Creative Commons Attribution-NonCommercial 4.0 International License (http://creativecommons.org/licenses/ by-nc/4.0/), which permits any noncommercial use, distribution, and reproduction in any medium, provided you give appropriate credit to the original author(s) and the source, provide a link to the Creative Commons license, and indicate if changes were made. 